Gut, 1986, 27, 946-953

\title{
Scintigraphic assessment of oesophageal motility: what does it show and how reliable is it?
}

\author{
M M MUGHAL, MARGARET MARPLES, AND J BANCEWICZ \\ From the University Department of Surgery, Hope Hospital, Salford
}

SUMmaRY Computer analysed transit of a liquid bolus containing $\mathrm{Tc}^{99 m}$ (RT) was compared with manometry for the detection of oesophageal motility disorders in 151 patients with a variety of oesophageal symptoms. Manometry was abnormal in 99 of whom 44 had abnormal RT (sensitivity $44 \%$ ); it was normal in 52 of whom 37 had normal RT (specificity $71 \%$ ). The commonest manometric abnormalities were non-specific motility disorders characterised by abnormalities of peristaltic amplitude, waveform or baseline. Radionuclide transit was abnormal in only $32 / 77(42 \%)$ of these. Achalasia, which is characterised by complete aperistalsis, was the least common diagnosis, but all five cases had abnormal RT. Simultaneous manometry and RT in 30 patients showed that the transit of a liquid bolus through the oesophagus is determined by the propagation rather than the form of the peristaltic contraction. Because non-specific motility disorders are common in clinical practice, RT is not a useful screening test for oesophageal dysmotility.

Oesophageal motility disorders are common causes of dysphagia and chest pain. ${ }^{1}$ In most cases oesophageal manometry is required for diagnosis and it has also been suggested that manometry should be done before antireflux surgery to exclude motility disorders which might lead to troublesome dysphagia after fundoplication. ${ }^{23}$ Manometry is uncomfortable, however, and requires considerable experience and expertise in its performance and interpretation.

Computer analysed liquid bolus transit of ${ }^{99 \mathrm{~m}}$ Technetium is a rapid, simple and non-invasive test which has been reported to be highly sensitive for the detection of oesophageal dysmotility. ${ }^{45}$ Radionuclide transit (RT) measurement also has the advantage that it can be done in any hospital using standard gamma camera equipment with minimal modification.

To date, however, the usefulness of RT has only been studied in small groups of patients, ${ }^{45}$ and there has been only one study which has looked at the exact relationship between peristaltic pressures and bolus transit. ${ }^{6}$ The present study was undertaken to determine this relationship and to assess prospectively the diagnostic value of RT in an unselected group of patients referred for oesophageal function studies.

Address for correspondence: Mr M M Mughal, FRCS. University Department of Surgery, Hope Hospital, Eccles Old Road, Salford M6 8HD.

Received for publication 29 November 1985.

\section{Methods}

\section{PATIENTS}

One hundred and fifty one consecutive patients ( 85 women, 66 men; mean age 47 years) referred for oesophageal function studies between January 1983 and June 1984 were studied. One hundred and thirteen patients had symptoms of reflux, 79 had dysphagia and 76 had central chest pain which had a different character from heartburn and was liable to be confused with cardiac pain. A frequent clinical problem was the assessment of patients with severe central chest pain who had only minor reflux symptoms. The overlap between the symptoms is shown in Figure 1. All patients underwent barium swallow with screening, endoscopy, 24 hour ambulant $\mathrm{pH}$ monitoring of the oesophagus and oesophageal manometry in addition to RT measurement. Manometry and RT were carried out within three days of each other. In addition, 30 patients underwent manometry during RT measurement.

Control RT data were obtained in 58 asymptomatic subjects ( 37 men, 21 women; mean age 31 years). Five subjects underwent two RT studies to assess the reproducibility of the test.

\section{TECHNIQUES}

Radionuclide transit measurement

The technique described by Russell and colleagues ${ }^{4}$ was used. The subject was positioned supine be- 


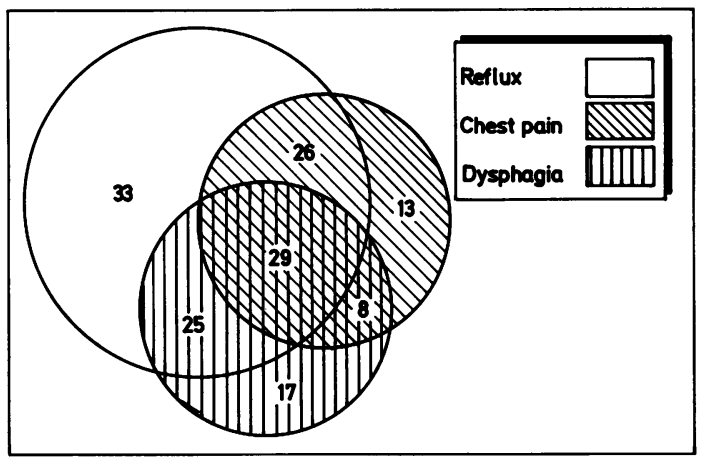

Fig. 1 Presenting symptoms in 151 patients.

neath a gamma camera linked to a computer with data storage facilities. This position was chosen to eliminate the effect of gravity which aids liquid bolus transit in the upright position and might hinder the identification of oesophageal dysmotility. The field of the collimator was adjusted to include the whole of the oesophagus and stomach, and a radioactive marker briefly placed over the cricoid to mark the upper end of the oesophagus for subsequent analysis. The subject then swallowed in a single gulp, a $10 \mathrm{ml}$ bolus of water labelled with $20 \mathrm{MBq}$ of $\mathrm{Tc}^{99 \mathrm{~m}}$ tin colloid while activity was recorded at the rate of one frame every 0.5 seconds for 50 seconds. Further swallows were not permitted during this period.

The data were then used to derive the total transit time. This was defined as the interval between the

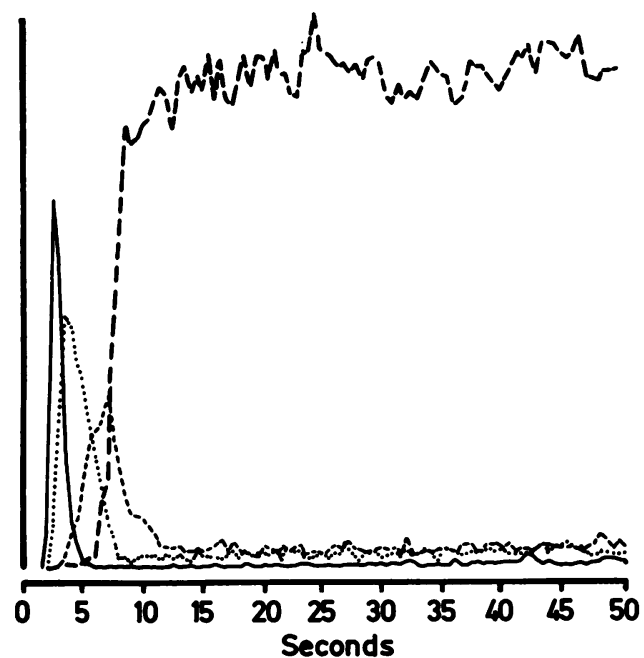

Fig. 2 Normal RT study. _ activity in proximal, .... mid, ---- distal oesophagus and - - -stomach. initial detection of activity in the oesophagus to its final clearance. Clearance was assumed when the radioactive count had fallen below $10 \%$ of the peak value as a steady low level of activity was noted in every case after passage of the bulk of the bolus through the oesophagus. Information about the dynamics of bolus transit was derived by electronically dividing the oesophagus into three equal segments and plotting activity in each segment and in the stomach against time (Fig. 2). In this way further classification into 'adynamic' and 'incoordinate' patterns was possible in cases of prolonged RT (Fig. 3).

\section{Manometry}

The Arndorfer miniature multilumen catheter with a low compliance pneumohydraulic infusion system was used (Arndorfer Medical Specialities Inc, Wisconsin, USA). Measurement of lower oesophageal sphincter pressure and assessment of motility in the
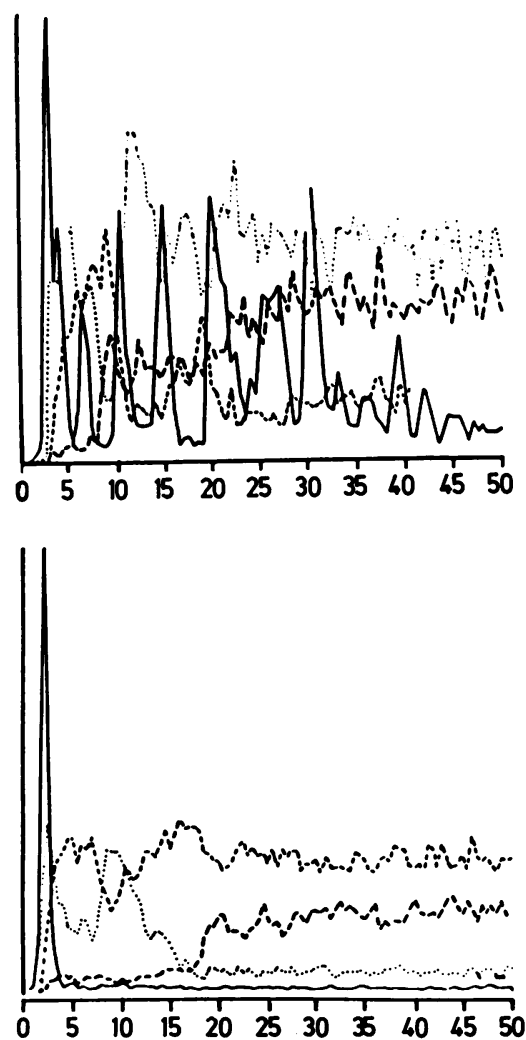

Fig. 3 Abnormal RT studies. The incoordinate bolus transit (above) can be distinguished from the adynamic pattern. Activity for different regions represented as in Fig. 2. 
body of the oesophagus was made by the station pull through technique ${ }^{7}$; The response of the oesophagus to at least 10 wet swallows was analysed, recording the propagation and form of the peristaltic wave. A non-propagated swallow was defined as one which failed to initiate a primary peristaltic contraction in the body of the oesophagus. Analysis of the waveform included measurement of the amplitude and duration of the peristaltic contraction. The frequency of spontaneous non-propagated contractions (tertiary waves), was also recorded.

The diagnosis of manometric abnormality was based on normal values in 30 asymptomatic subjects investigated in our laboratory. These were: $90 \%$ of swallows initiating propagated peristalsis; peristaltic wave amplitude $57.2 \pm 8.3 \mathrm{mmHg}$, duration $6 \pm 1.9$ sec, velocity $2.4 \pm 0.5 \mathrm{~cm} / \mathrm{sec}$, and $1.76 \pm 1.2$ tertiary contractions during five minutes of quiet respiration (all values means \pm standard deviations). These values are similar to those reported by Duranceau and associates. ${ }^{8}$

Our system of classifying manometric abnormalities was similar to that used by Russell and colleagues ${ }^{4}$ in their original paper on RT and that proposed by Benjamin and associates. ${ }^{9}$ The following definitions were used: Achalasia: complete failure of propagation of swallows with incomplete relaxation of the LOS on swallowing ${ }^{10}$; Idiopathic diffuse oesophageal spasm: chest pain and/or dysphagia associated with high amplitude $(>125 \mathrm{mmHg})$, non-propagated contractions in response to at least $30 \%$ of swallows with a functionally normal lower oesophageal sphincter ${ }^{11}$; Nutcracker oesophagus: high amplitude $(>125 \mathrm{mmHg})$, propagated peristaltic contractions with a functionally normal LOS. This manometric abnormality has been noted to be associated with chest pain and/or dysphagia ${ }^{12}$; Non-specific motility disorder: this is a collective term for a number of different manometric features which represent a slight departure from the 'normal' rather than gross abnormality. These abnormalities included peristaltic contractions of low amplitude ${ }^{9}$ - less than $25 \mathrm{mmHg}$ in the present study-or prolonged duration $(>7.5 \mathrm{sec}),{ }^{13}$ and waveforms with multiple peaks or followed by repetitive waves. ${ }^{14} \mathrm{~A}$ sustained increase in the baseline oesophageal pressure or 'spasm' was also considered abnormal. ${ }^{15} 16$ The presence of one or more of these abnormalities was considered to represent a non-specific motility disorder.

Simultaneous manometry and $R T$ measurement Patients first underwent a complete manometric study after which they were taken to the gamma camera room for the transit study with the mano- metry catheter in situ. After a suitable period for stabilisation a single RT measurement was done as described above while recording the propagation, amplitude and duration of the associated peristaltic wave and the frequency of any tertiary waves. In vitro studies had shown no significant adherence of $\mathrm{Tc}^{99 \mathrm{~m}}$ colloid to the manometry catheter and this was confirmed in vivo by scanning it after withdrawal at the end of the transit study. Studies in asymptomatic subjects showed similar RT patterns with or without the manometric catheter in situ, eliminating the possibility that the tube significantly affected liquid bolus transit.

\section{Twenty-four hour ambulant $\mathrm{pH}$ monitoring}

This was done using a glass $\mathrm{pH}$ electrode (Pye Unicam 140/E7) connected to a miniature digital recorder (Lectromed Multistore 5150, Lectromed Ltd, Jersey). The $\mathrm{pH}$ electrode was positioned $5 \mathrm{~cm}$ above the lower oesophageal sphincter, the level of which was determined from the manometric study. The test was conducted on an inpatient basis but patients were encouraged to indulge in normal activities as far as possible and to eat and drink normally. The $\mathrm{pH}$ trace was analysed and then scored using the method of Johnson and DeMeester. $^{17}$

\section{Barium studies and endoscopy}

Unprovoked reflux of barium, a peptic stricture or macroscopic oesophagitis with bleeding and ulceration were regarded as indicators of reflux, whereas an uncomplicated sliding hiatus hernia was not.

\section{Analysis of results}

All tests were analysed blindly. The definition of reflux took into account endoscopy, barium and $\mathrm{pH}$ studies. The presence of macroscopic oesophagitis with or without stricturing was considered significant irrespective of the $\mathrm{pH}$ results, though in fact, the latter was almost invariably positive in such cases. Much more commonly, the diagnosis of reflux was made on the basis of the $\mathrm{pH}$ study when endoscopy and barium studies were equivocal or normal. No assumptions were made regarding the distribution of data and therefore the Wilcoxon's rank sum test was used for comparison of numerical values.

\section{Results}

ASYMPTOMATIC SUBJECTS

The total transit time ranged between six and 27 seconds with a median of nine seconds and mean of $10 \cdot 14 \mathrm{sec} \pm 3 \cdot 41$ (SD). Although the data were not normally distributed, it was only slightly skewed because the median and mean are close. Therefore, 


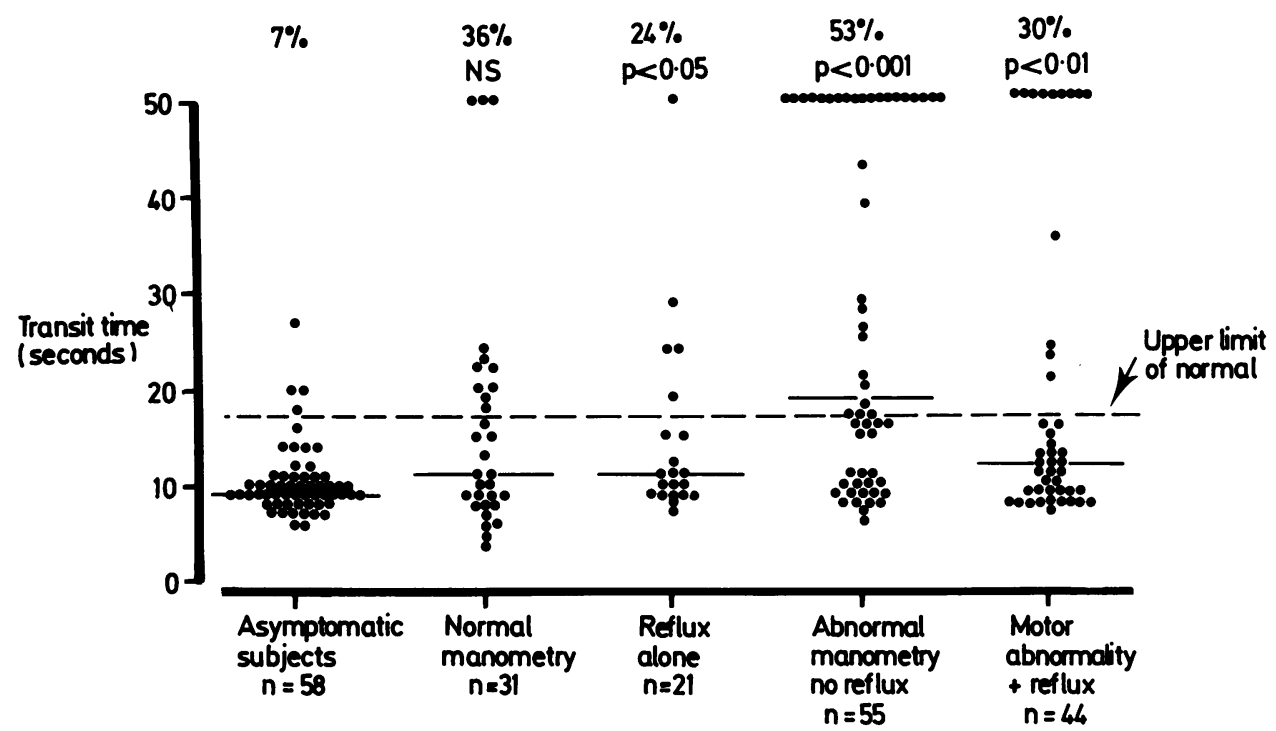

Fig. 4 Distribution of RT times according to diagnosis. Median values shown by horizontal line. p values forcomparison with asymptomatic subjects (Wilcoxon's rank sum test). \% refer to RT values $>17$ seconds (shown by dashed line).

a value of 17 seconds, which denotes the 95th centile (mean $\pm 2 \mathrm{SD})$ was chosen as the upper limit of normal transit time.

In two of the five subjects who had two RT measurements one study was normal and the other abnormal.

\section{PATIENTS}

\section{(a) Diagnostic value of $R T$ compared with manometry}

No evidence of reflux or manometric abnormality was found in 31 patients. The distribution of transit times in this group was not significantly different from the control group (Fig. 4). Twenty one had gastro-oesophageal reflux without an associated motor disorder. Fifty five had abnormal manometry but no reflux and 44 had both abnormal manometry and reflux. In all three groups with reflux and/or dysmotility, the transit times were significantly greater than in the control (asymptomatic) group. Despite this no more than half the patients in any group had transit times exceeding the upper limit of normal of 17 seconds. This is because of the wide scatter of transit times in all groups.

Altogether, 44 of the 99 patients with a manometric abnormality had abnormal RT and 37 of the 52 with normal manometry had normal RT. Hence, using manometry as the reference test, the overall sensitivity and specificity of RT for oesophageal dysmotility was $44 \%$ and $71 \%$ respectively. The manometric diagnoses were achalasia in five, diffuse oesophageal spasm in nine, the 'nutcracker' oesophagus in eight and non-specific motility disorder in 77 . In the 77 patients with non-specific motility disorder, the manometric abnormalities were multiple peaked waves in $84 \%$, repetitive contractions in $75 \%$, spasm in $66 \%$ and lowamplitude peristalsis in $22 \% ; 82 \%$ of the patients had more than one abnormality. Radionuclide transit was abnormal in all five patients with achalasia and in five of the nine with diffuse oesophageal spasm. Only $42 \%$ of those with a nonspecific motility disorder and only two of the eight with the 'nutcracker' oesophagus had abnormal RT (Fig. 5). Analysis of RT according to the underlying manometric abnormality in the 77 patients with nonspecific motility disorder failed to identify any single abnormality which was likely to be associated with abnormal RT (Table 1).

Of the 79 patients with dysphagia, only $39(49 \%)$ had abnormal RT whereas $59(75 \%)$ had abnormal manometry; of the 76 with chest pain, only $26(34 \%)$ had abnormal RT whereas $51(67 \%)$ had abnormal manometry.

A total of 59 RT studies were abnormal, the pattern of transit being 'adynamic' in 20 and 'incoordinate' in 39. All five patients with achalasia had an adynamic pattern while four of the five with diffuse oesophageal spasm had an incoordinate pattern. Patients with prolonged transit but normal manometry or non-specific motility disorder tended to have an inco-ordinate pattern (Table 2). 


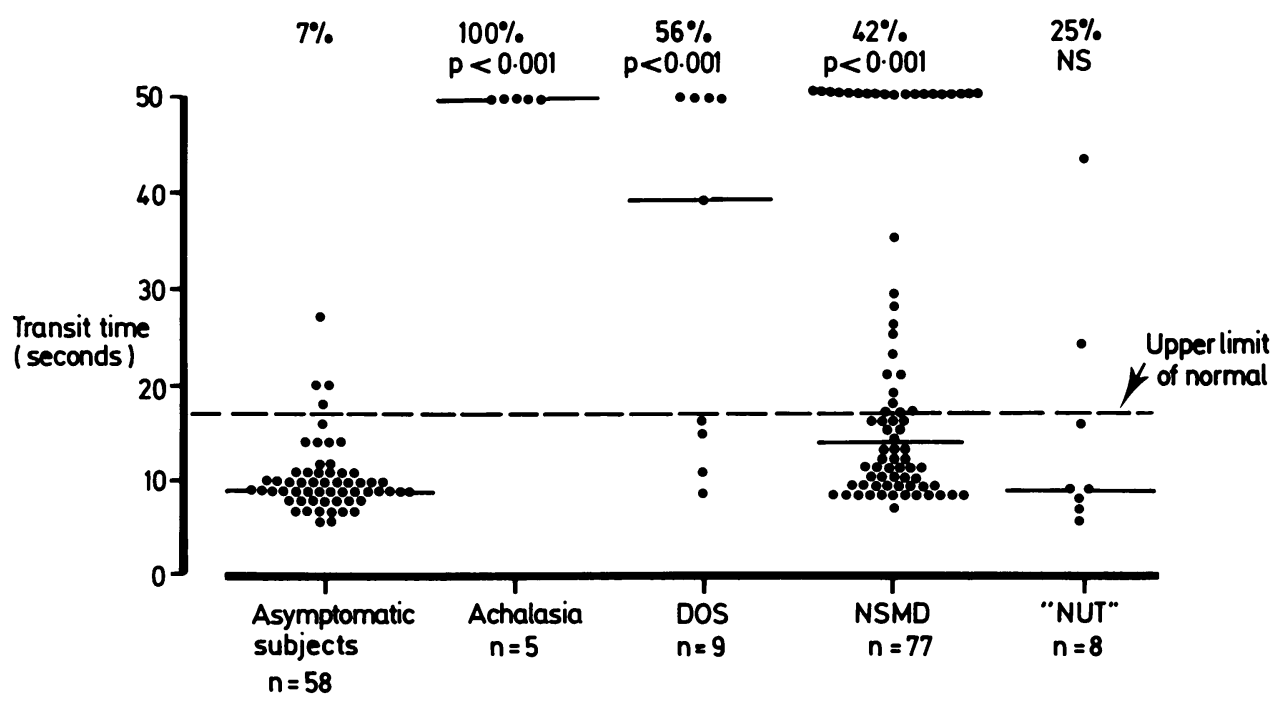

Fig. 5 Distribution of RT times according to manometric diagnosis.

(b) The relationship between peristalsis and transit Manometry was carried out during RT measurement in 30 patients (achalasia, one, diffuse oesophageal spasm three, non-specific motility disorder 16 and normal 10). Radionuclide transit was prolonged in 12 and normal in 18. Prolonged RT in all 12 cases was associated with a failure of the

Table $1 R T$ according to manometric abnormality in 77 patients with non-specific motility disorder

\begin{tabular}{lcl}
\hline Manometric abnormality & $R T$ abnormal & $R T$ normal \\
\hline Multiple peaked waves & 33 & 32 \\
Repetitive waves & 34 & 24 \\
Spasm & 30 & 21 \\
Peristaltic amplitude $<25 \mathrm{mmHg}$ & 7 & 10 \\
\hline
\end{tabular}

$\chi^{2}=2 \cdot 362, \mathrm{DF}=3, \mathrm{p}=0 \cdot 5(\mathrm{NS})$.

Table 2 Bolus dynamics in 59 patients with prolonged RT according to manometric diagnosis

\begin{tabular}{llll}
\hline & & \multicolumn{2}{c}{ Pattern of transit } \\
\cline { 3 - 4 } Manometric diagnosis & & Adynamic & Inco-ordinate \\
\hline Normal motility & & & \\
Non-specific motility disorder & $\mathrm{n}=15$ & 2 & 13 \\
'Nutcracker' & $\mathrm{n}=2$ & 10 & 22 \\
Diffuse ocsophageal spasm & $\mathrm{n}=5$ & 1 & 0 \\
Achalasia & $\mathrm{n}=5$ & 5 & 4 \\
Total & $\mathrm{n}=59$ & 20 & 39 \\
\hline
\end{tabular}

swallow to initiate a propagated peristaltic contraction. Conversely, in all 18 with normal RT, the associated contraction was propagated. The mean amplitude of the peristaltic contraction or the frequency of tertiary contractions in those with prolonged RT did not differ significantly from that in patients with normal RT $(p=0 \cdot 2)$ (Table 3$)$. Although the mean duration of the contraction was significantly greater in the group with prolonged RT $(p=0.01)$, it is recognised that non-propagated contractions often manifest abnormalities of form.

The implication of the finding from the simultaneous studies that the propagation of a peristaltic contraction is the major determinant of transit was tested in the main group of 151 patients undergoing

Table 3 Association between manometric variables and $R T$ in 30 patients during simultaneous manometry and $R T$ measurement

\begin{tabular}{lcl}
\hline Manometric variable & $\begin{array}{l}R T \text { normal } \\
n=18\end{array}$ & $\begin{array}{l}R T \text { abnormal } \\
n=12\end{array}$ \\
\hline $\begin{array}{l}\text { Failure of swallow to } \\
\text { propagate }\end{array}$ & $0 / 18$ & $12 / 12$ \\
$\begin{array}{c}\text { Amplitude of peristaltic } \\
\text { contraction (mmHg) }\end{array}$ & $57 \cdot 3 \pm 47.4$ & $58.9 \pm 19$ (NS) \\
$\begin{array}{c}\text { Duration of peristaltic } \\
\text { contraction (sec) }\end{array}$ & $5 \cdot 8 \pm 1 \cdot 7$ & $8.9 \pm 4 \quad \mathrm{p}=0.01$ \\
$\begin{array}{c}\text { Frequency of } 3^{\circ} \text { waves } \\
\text { (number/5 min) }\end{array}$ & $0.9 \pm 1$ & $1.5 \pm 1.5(\mathrm{NS})$ \\
\hline
\end{tabular}

All values are means \pm standard deviation.

Statistical analysis using Wilcoxon's rank sum test. 


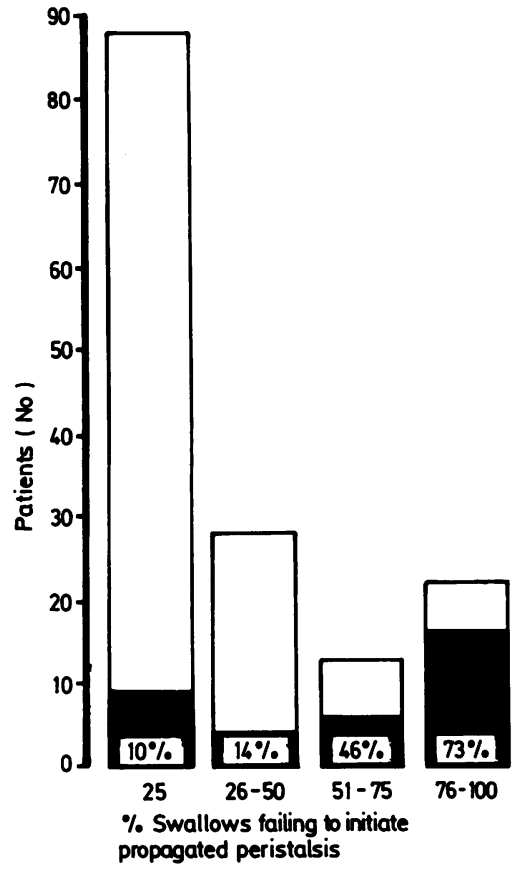

Fig. 6 Relationship between abnormal transit and failure of peristalsis in 151 patients. Shaded area denotes patients with transit time $>50$ seconds.

RT measurement and manometry on different occasions. For this analysis, the oesophageal response to at least 10 swallows taken during manometry was studied and the proportion failing to initiate a propagated contraction recorded for each patient. The 151 values so obtained were then divided into four groups ranging from less than $25 \%$ to more than $76 \%$ of swallows failing to initiate propagated peristalsis (Fig. 6). The number of patients with severe RT abnormality (transit time $>50$ seconds) in each group was then determined. The proportion of severe RT abnormality can be seen to increase in step with the degree of failure of peristalsis.

\section{Discussion}

Our study has shown that in the supine position, the transit of a liquid bolus through the oesophagus is determined only by the production of a peristaltic contraction in response to a swallow. Variation of the amplitude and form of the peristaltic contraction does not have a significant influence. Because of this RT is not as reliable a test of abnormal oesophageal motility as manometry which can detect other abnormalities of peristalsis. The overall sensitivity and specificity of RT as a screening test for oesophageal dysmotility was only $44 \%$ and $71 \%$ respectively, contrary to the results of previous studies. ${ }^{45}$ Analysis of the diagnostic yield of RT according to the presenting symptom showed it to be of little value in patients presenting with dysphagia or chest pain.

Radionuclide transit was measured and analysed as described by Russell $e t a l^{4}$ and Blackwell $e t a l,{ }^{5}$ but whereas these workers made two RT measurements in each patient, we only made one as both groups have shown RT to be highly reproducible. Thus, the discrepancy between our results and those reported previously is likely to be because of other factors such as patient selection and interpretation of manometry.

Russell and colleagues ${ }^{4}$ found prolonged RT in all 15 patients with known manometric abnormality. Five of the patients, however, had achalasia, three had diffuse oesophageal spasm, one had scleroderma and one had an aperistaltic oesophagus secondary to diabetes. In the light of our findings, it is not surprising that RT had a high yield in this selected group consisting mainly of aperistaltic disorders. By contrast, in our study less than $10 \%$ of the patients with a manometric abnormality had either achalasia or diffuse oesophageal spasm, the majority being classified as having a non-specific motility disorder. We did not find RT useful in identifying the non-specific motility disorders or the 'nutcracker' oesophagus.

As we had few patients with aperistaltic motility disorders, it could be argued that our poor results with RT are because of the way in which we classified manometric abnormalities. That the interpretation of manometry is controversial is highlighted by recent proposals for new ways of classifying motility disorders, ${ }^{914}$ and by the differences in the manometric findings in normal subjects investigated by different workers. ${ }^{8} 18$

The definitions we used were those used by Russell and colleagues in their original publication on RT. Of the total of 151 patients studied, $34.4 \%$ had normal manometry, $51 \%$ had a non-specific motility disorder, $9.3 \%$ had an aperistaltic disorder and $5.3 \%$ had the 'nutcracker' oesophagus. This distribution accurately reflects the spectrum of oesophageal motility found in over 600 patients investigated in our unit, and apart from the proportion of patients with high amplitude peristalsis, is similar to that reported by Clouse and Staiano. ${ }^{14}$ These workers found normal manometry in $29 \%$, what we would call a non-specific motility disorder in approximately $50 \%$ and aperistaltic disorders in $9.5 \%$ of 210 patients with a variety of oesophageal symptoms. Although Castell ${ }^{19}$ has reported a lower 
prevalence of non-specific motility disorder, this was in patients with a specific symptom - chest pain. Our study group, being light on patients with aperistaltic disorders, has put RT to a rigorous test as the true potential of a screening test can only be assessed when it is used in a population containing a fair proportion of 'true negatives' ${ }^{20}$

It should be said that manometry is not, of course, the perfect test of oesophageal motility, but merely the best that is currently available. Thus, having found prolonged RT in nine out of 14 patients with dysphagia but normal manometry, Russell and colleagues concluded that RT may be more sensitive than manometry. Indeed, we found abnormal RT in $15(28 \%)$ of the 52 patients with oesophageal symptoms and normal manometry compared with only four $(7 \%)$ of the 58 asymptomatic subjects, a result which would appear to support Russell's findings. An alternative, and in our view a more likely, explanation is that RT has a significant false positive rate. False positives may occur for a number of reasons. Firstly, the cause may be technical, for example a hesitant, double swallow of the bolus, or its pooling proximal to a tight stricture, in a diverticulum or in a herniated part of the stomach. ${ }^{21}$ Secondly, since $10-50 \%$ of swallows in $22 \%$ of asymptomatic subjects fall to generate propagated peristalsis ${ }^{18}$ there is likely to be a parallel false positive rate for $\mathrm{RT}$.

It is theoretically possible to increase the diagnostic yield of RT measurement by performing multiple swallows, although even this could only increase its sensitivity for motility disorders characterised by failure of propagated peristalsis. No further information would be obtained about peristaltic form. Any improvement in sensitivity achieved by this would have to be balanced against the increase in the length of the test, greater radiation exposure and the probable increase in the incidence of false positive tests. Some workers have suggested solid bolus transit measurement as a more physiological, and by implication a more sensitive method of assessing oesophageal motility. ${ }^{22}$ Unfortunately, there is considerable evidence that even in asymptomatic subjects, the transit of solids such as tablets and capsules is erratic, often requiring multiple swallows or an additional fluid bolus to complete. ${ }^{2324}$ This being so, it is difficult to envisage the advantage of solid bolus over liquid bolus transit measurement. We have now abandoned the routine use of RT measurement.

We are grateful for the expert assistance of Ann Ross, Gillian Cloherty, and Sheila Froggat for the manometric and $\mathrm{pH}$ studies and to Martin Ogden for the radionuclide tests.

\section{References}

1 Davies HA, Rhodes J. How often does the gut cause anginal pain? Acta Med Scand 1981; suppl 644: 62-5.

2 Bombeck CT, Battle WS, Nyhus LM. Spasm in the differential diagnosis of gastroesophageal reflux. Arch Surg 1972; 102: 477-83.

3 Pope CE. Esophageal motility - who needs it? Gastroenterology 1978; 74: 1337-8.

4 Russell COH, Hill LD, Holmes ER, Hull DA, Gannon RM, Pope CE. Radionuclide transit: a sensitive screening test for esophageal dysfunction. Gastroenterology 1981; 80: 887-92.

5 Blackwell JN, Hannan WJ, Adam RD, Heading RC. Radionuclide studies in the detection of oesophageal dysmotility. Gut 1983; 24: 421-6.

6 Richter JE, Blackwell JN, Wu WC, Cowan RJ, Johns DN, Castell DO. Assessment of liquid bolus transit (LBT) by simultaneous radionuclide transit and esophageal manometry. Gastroenterology 1983; 84: 1285.

7 Hurwitz AC, Duranceau A, Haddad JK. Disorders of esophageal motility. Philadelphia: Saunders, 1979.

8 Duranceau AC, Devroede G, LaFontaine E, Jamieson GG. Esophageal motility in asymptomatic volunteers. Surg Clin North Am 1983; 63: 777-86.

9 Benjamin SB, Richter JE, Cordova CM, Knuff TE, Castell DO. Prospective manometric evaluation with pharmacological provocation of patients with suspected esophageal motility dysfunction. Gastroenterology 1983; 84: 893-901.

10 Fisher R, Cohen S. Disorders of the lower esophageal sphincter. Ann Rev Med 1975; 26: 373-90.

11 DiMarino AJ Jr, Cohen S. Characteristics of lower esophageal sphincter function in symptomatic diffuse esophageal spasm. Gastroenterology 1974; 66: 1-6.

12 Benjamin SB, Gerhardt DC, Castell DO. High amplitude peristaltic esophageal contractions associated with chest pain and/or dysphagia. Gastroenterology 1979; 77: 478-83.

13 Herrington JP, Burns TW, Balart LA. Chest pain and dysphagia in patients with prolonged peristaltic contractile duration of the esophagus. Dig Dis Sci 1984; 29: 134-40.

14 Clouse RE, Staiano A. Contraction abnormalities of the esophageal body in patients referred for manometry. A new approach to the manometric classification. Dig Dis Sci 1983; 28: 784-91.

15 Olsen AM, Schlegel JF. Motility disturbances caused by esophagitis. J Thorac Cardiovasc Surg 1965; 50: 607-12.

16 Bancewicz J, Osugi H. Significance of oesophageal motility disorders. [Abstract]. Gut 1984; 25: A555.

17 Johnston LF, DeMeester TR. Twenty-four-hour pH monitoring of the distal esophagus: a quantitative measure of gastroesophageal reflux. Am J Gastroenterol 1974; 62: 325-32.

18 Nelson JL, Wu WC, Richter JE, Blackwell JN, Johns DN, Castell DO. What is normal esophageal motility? Gastroenterology 1983; 84: 1258.

19 Castell DO. Esophageal motility disorders: the specter of the spectrum. Dig Dis Sci 1985; 30: 188-9. 
20 Rose G, Barker DJP. Epidemiology for the uninitiated. London: BMA Publications, 1979.

21 Blackwell JN, Richter JE, Wu WC, Cowan RJ, Castell DO. Esophageal radionuclide transit test: potential false positive results. Gastroenterology 1983; 84: 1108.

22 Kjellén G, Svedberg JB, Tibbling L. Solid bolus transit by esophageal scintigraphy in patients with dysphagia and normal manometry and radiography. Dig Dis $S_{C i}$ 1984; 29: 1-5.

23 Applegate GR, Malmud LS, Rock E, Reilley JR, Fisher RS. 'It's a hard pill to swallow' or 'don't take it lying down'. Gastroenterology 1980; 78: 1132.

24 Fisher RS, Malmud LS, Applegate G, Rock E, Lorber SH. Effect of bolus composition on esophageal transit: concise communication. J Nucl Med 1982; 23: 878-82. 